\title{
John Dewey e a refutação do pensamento educacional clássico ${ }^{1}$
}

\author{
John Dewey's refutation of classical educational thinking ${ }^{2}$
}

Jürgen Oelkers*

\section{Resumo}

A obra Democracy and Education foi publicada pela primeira vez em 1916. John Dewey chamou-a "Uma introdução à Filosofia da Educação", o que significa que ela é mais do que uma descrição das relações empíricas entre "democracia", por um lado, e "educação", por outro. O que Dewey queria que aprendêssemos é que a democracia é a questão-chave de toda a moderna Filosofia da Educação. Ao contrário de apenas tangenciar a questão, a democracia está no seu cerne. Democracy and Education e suas ideias fundamentais completaram 100 anos, data que foi muito aclamada em todo o mundo da educação. E, de fato, Democracy and Education é até hoje uma referência central para todos que querem estudar o nexo filosófico entre a educação geral e o desenvolvimento da democracia.

Palavras-chave: Democracia. Desenvolvimento. Educação. Filosofia.

\section{Abstract}

Democracy and Education was first published in 1916. John Dewey called it "An Introduction to the Philosophy of Education", which means it is more than just a description of the empirical relations between "democracy" on one hand and "education" on the other. Dewey wanted us to learn is that democracy is the key question of every modern Philosophy of Education. It is not on the edge but at the heart of the matter. Democracy and Education and its basic ideas are now a hundred years old and that date was much acclaimed throughout the world of education. And in fact Democracy and Education until today is a central reference for all who want to study the philosophical nexus between general education and the development of democracy.

Keywords: Democracy. Development. Education. Philosophy.

Recebido em 18/08/2017 - Aprovado em 23/11/2017

http://dx.doi.org/10.5335/rep.v25i1.8029

Professor emérito do Instituto de Ciências da Educação da Universidade de Zurique, Suíça. Destaca-se, entre sua vasta produção científica, a obra John Dewey und die Pädagogik (John Dewey e a Pedagogia). E-mail: oelkers@ife.uzh.ch 
Em 1911, no segundo volume da Cyclopedia of Education, de Paul Monroe, Dewey define a relação entre democracia e educação. A enciclopédia de Monroe foi presumivelmente a primeira enciclopédia pedagógica a incorporar o conceito de "Democracia e Educação". Sob esse título, Dewey apresentou não sua própria teoria, mas um resumo da discussão norte-americana desde meados do século. De acordo com o autor, a democracia e a educação estão ligadas entre si de duas maneiras: primeiro, para se consolidar, a democracia precisa de cidadãos educados; e, em segundo lugar, as ideias democráticas moldam a própria educação, nomeadamente a constituição e o processo do sistema escolar público (DEWEY, 1985a, p. 417-418). Os pré-requisitos para isso são o respeito à individualidade e, portanto, a superação da autoridade feudal no processo de diferenciação da sociedade:

A democracia inevitavelmente carrega consigo um maior respeito pelo indivíduo como indivíduo, maior oportunidade de liberdade, independência e iniciativa em conduta e pensamento e, consequentemente, aumento da demanda por respeito fraterno e por responsabilidades autoimpostas e assumidas voluntariamente (DEWEY, 1985a, p. 418). ${ }^{3}$

Dewey escreveu inúmeras contribuições para a enciclopédia de Monroe, nas quais ele se referiu em várias passagens a Charles Eliot, que tinha estabelecido temas centrais da "nova educação". A nova educação marcaria a diferença do sistema americano de educação com aquele da Inglaterra ou da Europa Continental, por exemplo, em relação à liberdade na educação, à maior individualização do ensino e, acima de tudo, à função da educação numa sociedade democrática. ${ }^{4}$ Eliot é também uma das fontes da famosa formulação de Dewey segundo a qual a educação é uma "reconstrução contínua da experiência" (DEWEY, 1985a, p. 431). ${ }^{5}$ Dessa forma, a educação não é limitada nem pode ser especificada; é simplesmente o processo contínuo de ajuste inteligente para cada nova situação na vida.

Essa mudança de teoria tem consequências: a individualidade não é mais, como na tradição europeia de cultivar-se, o mundo "interno" do sentimento ou do pensamento contra o mundo "externo" da sociedade. De fato, o dualismo do indivíduo e da sociedade em geral torna-se questionável. A sociedade não é uma "coisa" ou um "corpus", mas uma interação complexa entre indivíduos e grupos. Todas as instituições ou processos sociais são soluções para problemas, que podem ser alterados em face de novos problemas e novas soluções. Essa teoria social da interação torna impossível considerar a "educação" como um efeito duradouro do cultivo interno. Para a teoria pragmatista, a educação é um processo contínuo que se refere à interação social numa sociedade democrática e não pode usar qualquer autoridade não questionada para que possa concretizar-se.

Os requisitos para uma reforma educacional democrática têm sido um tema no debate público americano desde meados do século XIX. Em 1850, Edward Mans- 
field usou o termo educação americana. Esse termo foi justificado com referência à ideia de república e não de educação clássica. A educação americana, segundo Mansfield, remonta a três princípios - a saber, a constituição americana, as ciências naturais e, portanto, a civilização moderna -, assim como à ideia de cristandade, tal como é estabelecida na Bíblia (MANSFIELD, 1850, p. 62).

Reflexões semelhantes podem ser encontradas em inúmeras publicações na década anterior à Guerra Civil Americana. Faz-se referência a uma educação para as pessoas, e não apenas para a elite (popular education) (MAYHEW, 1850), à superação do sistema educacional e seu modus operandi antidemocrático (ANDREWS, 1853) ou à renovação da educação em face do precário estado material e curricular das escolas da época (Revival of education) (MAY, 1855).

Uma educação pública para todos, adaptada aos objetivos de uma sociedade civil, tinha sido proposta em 1854 pelo presidente da Brown University, Francis Wayland. O enorme progresso da indústria, de acordo com Wayland, o crescimento e a distribuição desigual da riqueza na sociedade, o aumento da mobilidade e a flexibilização da intercomunicação social, tudo isso sugere uma forma pública de educação, que cada pessoa deve alcançar, porque todos são afetados, direta ou indiretamente, por todos os desenvolvimentos na cultura e na sociedade. Esse argumento foi um tema central do discurso público sobre o futuro da educação mais de sessenta anos antes da publicação de Democracy and Education. Francis Wayland argumentou que não é o Estado que é decisivo nesse processo de educação democrática, mas o espírito do público, que não pode ser administrado e deve assumir a sua própria forma:

Assim, a mente pública está sempre alerta. Todo homem está continuamente fazendo julgamentos, verdadeiros ou falsos, mas ainda assim julgamentos. Não só em relação aos acontecimentos de sua própria cidade ou aldeia, mas também aos acontecimentos de toda a República e do mundo (WAYLAND, 1855, p. 18).

A solução para os problemas centrais da sociedade industrial em rápido desenvolvimento não é a inclusão social rígida de indivíduos ou grupos, nem a distribuição feita pelo Estado, mas a mobilidade e a educação. A sociedade civil requer cidadãos que possam participar de assuntos públicos.

Após a guerra civil em 1869, Charles William Eliot cunhou o termo "nova educação" ${ }^{6}$ Ele foi concebido para descrever uma reforma prática da educação superior nos Estados Unidos, orientada para as ciências naturais, as línguas modernas e a economia política. ${ }^{7}$ Como presidente de longa data da Universidade de Harvard, Charles Eliot defendeu o conceito de que a educação deveria ter um foco central na aplicabilidade e na eficiência social (ELIOT, 1909b). Por isso, o estado da pedagogia também foi criticado: "A história da educação está cheia de teorias nascidas mortas; 
a literatura do assunto é composta em grande parte por teorização; quem quer que leia isso muito se voltará com alívio infinito para as lições da experiência" (ELIOT, 1869 , p. 204). Com uma teoria tão especulativa ou "idealista", o problema de como uma educação democrática pode ser desenvolvida não pôde ser enfrentado. Isso já havia sido afirmado por Mansfield (1850, p. 62), a metafísica não se enquadra na educação moderna, a menos que se torne uma ciência.

O que John Dewey faz em Democracy and Education é resumir essas discussões do século XIX e dar-lhes uma expressão filosófica adequada. Para fazer isso, ele tem que refutar as teorias clássicas da educação, de Platão ao Iluminismo, e redefinir a educação com os recursos da filosofia pragmática. Então, o que está estabelecido no sétimo capítulo de Democracy and Education como "a concepção democrática na educação" pressupõe que uma teoria filosófica da educação que se encaixa nessa exposição não está simplesmente disponível, mas deve, antes de tudo, ser criada.

O primeiro e decisivo termo da teoria de Dewey é aquele que tem sido muito usado ao longo da história da educação, a saber, "crescimento" ou "desenvolvimento". O termo desempenha um papel central na antropologia do século XVIII e também no Romantismo e na subsequente pedagogia do século XIX. Dewey mantém o termo "crescimento", mas dá-lhe um significado totalmente novo, que é retirado do conceito orgânico de crescimento, por um lado, e de concepções finalistas de desenvolvimento, por outro. Fundamental não é o crescimento de uma qualidade natural no tempo, mas o processo de ajuste contínuo diante de novos problemas. Essa visão básica exclui qualquer forma de teleologia, a qual, no entanto, constitui o núcleo de quase todas as teorias educacionais. As teorias educacionais clássicas são "teorias de objetivo", que podem ignorar o verdadeiro processo de experiência.

Dewey inverte essa relação de objetivos e experiência. O uso do termo "crescimento" ou "desenvolvimento" é errado em contextos educacionais se isso implica qualquer tipo de teleologia, "que seja um movimento em direção a um objetivo fixo" (DEWEY, 1985b, p. 55). Após Darwin, uma teleologia da natureza sob qualquer forma não é mais defensável e deve ser descartada; no entanto, na pedagogia do século XIX, essa teleologia é usada rotineiramente. De Rousseau a Fröbel, nas teorias educacionais, a "natureza" é sempre sinônimo de "desenvolvimento", o que deixa implícito que o desenvolvimento está sempre se movendo em direção a um objetivo específico. Esse objetivo é alcançado com o movimento; portanto, não faz parte do processo e, consequentemente, não pode ser corrigido pelo processo.

Fundamental para isso é a metáfora do "caminho" ou do "curso", que, desde a República de Platão, tem exercido influência considerável sobre a linguagem e a imaginação da educação (GUSKI, 2007). A educação não leva apenas de estados 
inferiores para estados superiores; ela só tem um caminho e um objetivo à sua disposição. O caminho e o objetivo estão vinculados, mas o objetivo é fixado independentemente do caminho. Ele está "dado", é um telos, no sentido antigo; os objetivos podem ou não ser alcançados, mas não mudados: "Considera-se que o crescimento tem um fim, em vez de ser um fim” (DEWEY, 1985b, p. 55, grifo do autor).

Para Dewey, o "crescimento" é um período sempre limitado, que encontra seu fim para começar de novo, enquanto, na teoria clássica, o desenvolvimento alcança ou perde seu objetivo predefinido. A educação refere-se a uma quantidade de tempo ininterrupta, final e fixa, enquanto que, para Dewey, a educação é construída a partir de sequências de experiências que podem ser interrompidas, nunca são finais e podem ser mais longas ou mais curtas, de acordo com suas funções.

A filosofia teleológica da educação tem que aceitar três falácias educacionais: primeiro, os poderes instintivos ou inatos da criança desaparecem nas teorias educacionais, eles apenas prejudicariam suas expectativas; segundo, a situação básica da educação parece permanecer fixa, de modo que nada precisa ser empreendido para adaptar a aprendizagem a novas situações; e, terceiro, a educação favorece meios que garantem a acumulação de habilidades automáticas, pois, caso contrário, o crescimento contínuo em direção ao objetivo único dificilmente poderia ser alcançado: "Em todos os casos, o ambiente adulto é aceito como um padrão para a criança. Ela deve ser levada para ele" (DEWEY, 1985b, p. 55). O objetivo é a conformidade com o objetivo, e, em seguida, qualquer outro comportamento pode ser apenas uma coisa: "travessura ou anarquia" (DEWEY, 1985b). Isso também explica a posição do professor: "Uma vez que o fim do crescimento está fora e além do processo de crescimento, deve-se recorrer aos agentes externos para induzir o movimento em direção a ele" (DEWEY, 1985b, p. 56).

O gouverneur de Rousseau é concebido dessa forma, assim como a Mãe Gertrud de Pestalozzi e, não menos importante, o Kindergartener de Fröbel e, portanto, os professores de educação progressiva. Em todos esses modelos, o professor deve dar por certa a natureza da criança e apoiar de fora o que se desenvolve. No entanto, isso exige ou o conhecimento completo de um processo que está apenas se desenvolvendo, ou então uma adição à natureza, com a qual o crescimento pode ser promovido de fora.

Mas, de acordo com Dewey, "na realidade, não há nada a que o crescimento seja relativo exceto mais crescimento" (DEWEY, 1985b, p. 56); a partir disso, "não há nada a que a educação se subordine, exceto mais educação" (DEWEY, 1985b, p. 56). A criança, portanto, não é "imatura", mas autoatuante. A "imaturidade" emerge como uma atribuição em comparação com os adultos: às crianças faltam certos traços desejados. Então, a educação tem que compensar um déficit, e isso 
pressupõe que ensinar nada mais é do que preencher com conhecimento um buraco moral (DEWEY, 1985b). Mas essas expectativas, de acordo com Dewey, só podem enganar a teoria. Não há nada para "preencher", as crianças aprendem, assim como o fazem os adultos, mas nunca estão em status de inferioridade:

Uma vez que a vida significa crescimento, uma criatura viva vive tão verdadeira e positivamente em uma etapa quanto em outra, com a mesma plenitude intrínseca e as mesmas reivindicações absolutas. Portanto, a educação significa a iniciativa de fornecer as condições que asseguram o crescimento ou a adequação da vida, independentemente da idade (DEWEY, 1985b, p. 56).

A vida é crescimento no sentido de que a mudança é constantemente experimentada, e as adaptações precisam ser feitas. Não existe um objetivo supremo que possa orientar o desenvolvimento. Dewey, em outras palavras, nega a teoria da maturação e, portanto, o fim da educação. Se a educação e a experiência são indistinguíveis, e a vida é crescimento, não pode haver um fim para a educação, nem um ponto culminante. As metáforas anteriores que orientam a educação, como os "passos" da vida ou a "culminação" no ponto mais alto do desenvolvimento, seriam, portanto, substituídas.

No quinto e no sexto capítulos de Democracy and Education, Dewey discute cinco conceitos de educação que se opõem à sua própria teoria e que devem ser refutados para favorecer tal teoria. Sua teoria, conforme Dewey informa, "contrasta fortemente com outras ideias que influenciaram a prática" (1985b, p. 59). O que se entende, neste ponto, são conceitos de educação que desempenharam um papel na pedagogia americana do século XIX e que foram vistos como indispensáveis para a discussão da "educação". Não são sempre teorias elaboradas. O critério de seleção é a influência da prática. Dewey examina formas de reflexão que são usadas na compreensão pública e profissional da educação e com as quais uma ou outra teoria foi ligada. O objetivo de Dewey é analisar sua adequação à questão da relação entre democracia e educação.

O primeiro desses conceitos vê a educação como um equipamento ou uma preparação para a vida. A preocupação é com a metáfora presumivelmente mais eficaz na história do pensamento pedagógico. A metáfora assume o valor de educação para o futuro da criança e da sociedade, o que desvaloriza o presente. De acordo com essa ideia, as crianças ainda não são membros plenos da sociedade, são colocadas em uma reserva pedagógica: "Elas são vistas como candidatas; elas são colocadas na lista de espera" (DEWEY, 1985b, p. 59). Mas as crianças vivem, em um sentido quase literal, no presente; o futuro para o qual estão sendo preparadas está "muito distante", o processo de "equipar" é, de fato, dificilmente concebível e 
exige um alto grau de recompensas e punições artificiais, sem de fato alcançar uma preparação real para situações de vida futura.

No seu cerne, esse é um argumento do Emile, de Rousseau (1969). Qualquer educação, afirma Rousseau, é uma barbaridade que sacrifica o presente da criança em nome de um futuro incerto e prepara para algo (préparer) que nunca acontece conforme o esperado (O.C. IV/S. p. 301). A preocupação com a educação não é ganhar tempo, mas perder (O.C. IV/S, p. 323). No entanto, em Democracy and Education, o argumento é usado menos radicalmente. Dewey não afirma que a educação não pode ou não deve ter nada a ver com o futuro, o que Rousseau conseguiu fazer porque pressupôs fases de desenvolvimento natural. Para Dewey, o crescimento está influenciando o futuro; o erro não está aí, mas no fato de a educação apostar tudo na preparação do futuro. Mas sempre se pode influenciar o presente, que, como Dewey entende, "funde-se imperceptivelmente" com o futuro (DEWEY, 1985b, p. 61). Portanto, o ganho de educação nunca é certo, e o futuro nunca é equivalente aos objetivos da educação.

Dewey chama a segunda falsa teoria da educação de Educação como desdobramento. Essa doutrina está associada a três autores - Fröbel, Hegel e Rousseau -, que defendem três conceitos que, apesar de suas diferenças, compartilham um núcleo comum. Esse núcleo é descrito por Dewey como “desenvolvimento como desdobramento":

O desenvolvimento é concebido não como um crescimento contínuo, mas como o desdobramento de poderes latentes em direção a um objetivo definido. O objetivo é concebido como completude, perfeição. A vida em qualquer etapa que não tenha alcançado ainda esse objetivo é apenas um desdobramento em direção a ele (DEWEY, 1985b, p. 61).

Os “objetivos" também podem ser ideais. Eles são "absolutos" no sentido de que todo o desenvolvimento deve orientar-se para eles e apenas para eles. Em Education of man, de Fröbel, ou Philosophy of history, de Hegel, os objetivos existem de forma latente, em desenvolvimento, como "potenciais" ou "disposições não desenvolvidas", que são gradualmente conduzidas à sua conclusão: "O que se denomina desenvolvimento é o gradual processo de tornar explícito e externo o que está imerso" (DEWEY, 1985b, p. 62).

Fröbel chama esse processo de desenvolvimento da natureza para sua completude, e Hegel, de desenvolvimento da história para o espírito absoluto. Em ambos os casos, o objetivo é definitivo; o desenvolvimento, de acordo com Dewey, não passa do "desdobramento de um princípio latente pronto" (DEWEY, 1985b, p. 63). De fato, a maioria das teorias educacionais do século XIX é estabelecida dessa maneira. Os objetivos são estados finais, que podem ser alcançados ou perdidos, sem que se possa alterá-los pelo desenvolvimento. Os objetivos são indubitáveis também porque 
são garantidos por meio das teorias metafísicas da "natureza", da "história", do "espírito" ou da "sociedade". Algumas delas estão ligadas, como a teoria hegeliana da história com a teoria marxista da sociedade, ou as teorias românticas da natureza com o espírito fröebeliano da criança. Nenhuma delas simplesmente se referiu à vida e à experiência de crianças e adultos dentro de uma sociedade democrática.

As teorias empíricas da educação dificilmente estão presentes na pedagogia europeia continental em torno de 1900 ou são atribuídas à psicologia. Conferências internacionais anteriores à Primeira Guerra Mundial, como o Congresso de Educação Moral de 1912, em La Haye, mostraram pequenos sinais do método "científico" de aprendizagem que Dewey tinha proposto anos antes. Nesses contextos do discurso educacional, não existe uma reconstrução permanente da experiência e, se há referências à ciência e à educação, estão ligadas não à democracia, mas à "religião da humanidade" (COMTE RENDU, 1913, p. 33).

A questão básica do congresso era se a educação poderia ser laica ou deveria ser religiosa, e, em ambos os casos, os oponentes defenderam fortes objetivos idealistas que a educação moral deveria atingir. Mas, mesmo as teorias psicológicas tendem a compreender o "desenvolvimento" teleologicamente, o que também pode ser mostrado por Piaget e a éducation nouvelle de Genebra.

Dewey critica consistentemente também Rousseau, a quem Piaget sempre se referiu. Rousseau, de acordo com Dewey, concebe o "desenvolvimento natural" da criança como um desdobramento de potenciais, em que nenhum terceiro deve interferir, porque e na medida em que a sociedade é não natural (DEWEY, 1985b, p. 65). Mas a natureza não é o "padrão" da educação, como muitos reformistas no final do século XIX presumiram. Provavelmente, essa referência à educação natural pode ser usada para criticar a prática educacional, mas não mais que isso; a natureza não faz simplesmente o seu trabalho "na" criança. Não é um agente, embora os rousseauistas entendam a "natureza" como se ela desse ao desenvolvimento humano sua lei e seu objetivo, aos quais a educação simplesmente tem que obedecer: "O uso construtivo da inteligência na previsão e elaboração é desconsiderado; devemos apenas sair do caminho e permitir que a natureza faça o trabalho" (DEWEY, 1985b, p. 119).

Em terceiro lugar, Dewey traz para a cena a Educação como treinamento das faculdades. O conceito remonta a John Locke. De acordo com ele, o espírito humano possui certos poderes, como atenção, observação, retenção, comparação, abstração, composição, etc., que podem ser influenciados de tal forma que um "hábito treinado" emerja. Os meios para isso são o exercício e a repetição, nos quais os níveis de dificuldade se regulam pelo sucesso do que foi alcançado. Essa teoria é o pano de fundo do processo de escolarização no século XIX, mas nem as faculdades 
"internas" pressupostas existem, nem podem ser treinadas como músculos. Somente uma qualidade marginal de educação depende do treinamento; aquele que deve aprender decorando não tem garantia de ter entendido o que foi aprendido (DEWEY, 1985b, p. 69-70). A repetição constante não torna a qualidade melhor.

De acordo com Dewey, o erro central da teoria reside na separação de atividades e capacidades de aprendizagem a partir do assunto. Contudo: "Não existe tal capacidade de ver, ouvir ou lembrar em geral; existe apenas a capacidade de ver ou ouvir ou lembrar algo" (DEWEY, 1985b, p. 70, grifo do autor). O sensualismo do século XIX implica facilidades internas isoladas que podem ser cultivadas como tal. Mas os órgãos dos sentidos estão sempre relacionados a ambientes de aprendizagem e nunca são acessíveis isoladamente em si mesmos: "Consequentemente, poderes como observação, lembrança, julgamento e gosto estético representam resultados organizados da ocupação de tendências inatas ativas com certos assuntos" (DEWEY, 1985b, p. 71, grifo do autor).

Assim, de acordo com Dewey, não há influência direta sobre as qualidades psicológicas de crianças e adultos. O critério para a seleção de assuntos de aprendizagem é sempre "social” (DEWEY, 1985b, p. 72), e não psicológico. Essa é uma das razões pelas quais também a quarta teoria é rejeitada, a saber, a Educação como formação. O melhor representante dessa teoria, diz Dewey, é Herbart. Por trás da teoria da formação, está a psicologia da percepção de Herbart, que supostamente representa uma nova abordagem da educação. ${ }^{8}$ Herbart nega a teoria do desenvolvimento orgânico, bem como a teoria das faculdades internas. Sua psicologia não é nem orgânica, nem sensualista, mas descreve, com fórmulas matemáticas, o movimento interno da massa de percepções. Dessa forma, as leis do espírito ${ }^{9}$ podem ser descritas e devem ser vistas como base para a educação. Ela não é, portanto, nem crescimento natural, nem treinamento:

É antes a formação do espírito pela criação de certas associações ou conexões de conteúdo por meio de um assunto apresentado de fora. A educação prossegue, por instruções tomadas em um sentido estritamente literal, uma construção no espírito a partir de fora (DEWEY, 1985b, p. 75).

$\mathrm{O}$ que Herbart chamou de erziehender Unterricht (instrução educativa) baseia-se no pressuposto de que nenhuma percepção é perdida, e de que toda a nova percepção deve ser assimilada às antigas. As apresentações antigas podem cair abaixo do limiar da consciência, mas permanecem presentes, uma ideia que Freud usou mais tarde para sua teoria do inconsciente. O espaço interior do espírito é ilimitado, a educação não conhece limites e tem apenas um limiar real, o da assimilação do novo. Essa também é uma ideia poderosa que foi utilizada, por exemplo, por Piaget, para sua teoria do desenvolvimento. 
Para Dewey, o defeito da teoria da formação de Herbart reside, acima de tudo, no isolamento do espírito humano. A psicologia de Herbart ignora completamente a interação entre o organismo e o meio ambiente, ou aquela que Dewey chama de ajuste inteligente. Em termos pedagógicos, Herbart oferece uma teoria de professores, o que fortalece os professores e não a aprendizagem: "A filosofia é eloquente sobre o dever do professor em instruir os alunos; é quase silenciosa em relação ao seu privilégio de aprender" (DEWEY, 1985b, p. 77). A teoria contém quase tudo sobre educação, com exceção da essência: "energia vital buscando oportunidade de exercício efetivo" (DEWEY, 1985b, p. 77). A ideia de formação do espírito é levar a um resultado conclusivo, como Dewey afirma, a um "mobiliário" do espírito (DEWEY, 1985b, p. 76), o que ignora totalmente o fato de que a experiência precisa se reconstruir constantemente: "A formação não é apenas uma formação de atividades inatas, mas ocorre através delas" (DEWEY, 1985b, p. 77-78, grifo do autor).

A teoria final que Dewey ataca é a do paralelismo, representada por Herbart, mas sobretudo por seus seguidores no século XIX, um movimento internacional de "educação científica" chamado "herbartianos". Desse ponto de vista, a educação é recapitulação ou retrospecção. A fundamentação para a educação é novamente a ideia de desenvolvimento, mas agora entendida como repetição ou recapitulação: "O indivíduo se desenvolve, mas seu desenvolvimento adequado consiste em repetir, em etapas ordenadas, a evolução passada da vida animal e da história humana" (DEWEY, 1985b, p. 78).

Os seguidores de Herbart pressupuseram etapas de desenvolvimento cultural e alegaram que a educação da criança se produziria em paralelo com essas etapas. Seria, assim, uma repetição do passado, uma ideia que, em uma forma generalizada, determinou o ensino superior até a disputa entre Dewey e Maynard Hutchins nos anos 1930. Tal disputa ainda não desapareceu completamente hoje, como pode ser demonstrado pelas discussões da literatura canônica, segundo as quais os maiores livros do passado devem ter um foco central na educação.

Todavia, a preeminência do passado cultural não é o ponto principal na crítica de Dewey. Acima de tudo, Dewey rejeita a ideia de hereditariedade, no sentido de que "a vida passada de alguma forma predeterminou os principais traços de um indivíduo, e que eles estão tão fixos que pouca mudança significativa pode ser introduzida neles" (DEWEY, 1985b, p. 80). Essa crítica às fundamentações biológicas é transferida para o uso cultural da teoria. O presente não depende do passado; o passado pode ser pesquisado e compreendido, mas ele não determina o futuro. A teoria das épocas culturais dos herbartianos e também a educação clássica da escola de gramática alemã "tendem a fazer do passado um rival do presente e do presente uma imitação mais ou menos fútil do passado" (DEWEY, 1985b, p. 81). 
Isso, no entanto, contradiz sobretudo a teoria do tempo: “O presente não é apenas algo que vem depois do passado; muito menos algo produzido por ele. O presente é o que a vida é ao deixar o passado para trás" (DEWEY, 1985b, p. 81).

Esse argumento, que recomenta Henri Bergson, também é usado indiretamente contra a "lei biogenética", de Ernst Haeckel. De acordo com essa lei, que foi formulada definitivamente em 1872, a ontogênese "recapitula" a filogênese, uma ideia que foi generalizada entre os intelectuais americanos e europeus antes de 1900. Para Dewey, a teoria morfológica de Haeckel não é convincente devido ao fato de que o tempo flui e não pode ser "represado". O passado não pode ser estocado; só pode ser um estímulo da imaginação do presente. Assim, o passado é relevante somente num sentido estético. A respeito disso, Dewey afirma: "O passado é um grande recurso para a imaginação; acrescenta uma nova dimensão à vida, mas na condição de ser visto como o passado do presente e não como um mundo outro e desconectado" (DEWEY, 1985b, p. 82).

O que permanece é a própria teoria de Dewey, que vê a educação como reconstrução. Ela deve superar a distinção entre o interno e o externo e, assim, dissolver os dois dogmas fundamentais da pedagogia (OELKERS, 1994, 2004), que veem a educação como "desdobramento", por um lado, e como "formação", por outro:

Em contraste com as ideias tanto de desdobramento de poderes latentes de dentro quanto de formação a partir de fora, seja por natureza física ou pelos produtos culturais do passado, o ideal do crescimento resulta na concepção de que a educação é uma constante reorganização ou reconstrução da experiência. Tem todo o tempo um fim imediato e, na medida em que a atividade é educativa, atinge esse fim - a transformação direta da qualidade da experiência (DEWEY, 1985b, p. 82).

Somente após essa discussão crítica das teorias rivais da educação, Dewey estabeleceu a relação entre democracia e educação. Para sintetizar o resultado: "Educação" não produz algo artificial e não conclui nada, mas acrescenta algo. Deve-se ter como certo que as crianças já possuem experiência social. Não há tábula rasa de experiência, assim como não há ponto zero de desenvolvimento. A educação pode, no entanto, "reorganizar" a experiência, ou seja, adicionar algo ao significado existente ou melhorar as habilidades para moldar as experiências subsequentes. A esse respeito, não restava nada para Dewey a não ser estabelecer, nas primeiras cem páginas de Democracy and Education, uma clara ruptura com o que havia sido, desde o início do século XIX na historiografia da educação, chamado "tradição pedagógica". Portanto, o que Dewey explicou em 1916 foi uma modernização da teoria da educação por meio do pragmatismo. A “educação" deve ser desmistificada, ou seja, relacionada apenas a si mesma, sem salvaguardas transcendentais. 
Em última análise, o problema era como uma teoria da relação entre democracia e educação poderia ser ela mesma democrática. Nesse caso, deve conseguir existir sem a filosofia do passado, portanto sem a "alma" de Platão, a "natureza" de Rousseau ou a "história" de Hegel. As autoridades desse tipo só podem ser adotadas ou dispensadas. "Darwinista", no conceito de Dewey, é a ideia de desenvolvimento por meio do ajuste, pelo qual todos os conceitos anteriores de "desenvolvimento" ou "crescimento" sofreram uma crítica clara. Eles não conseguem se encaixar nos dois conceitos fundamentais da democracia, a saber, a "participação" e o "reajuste flexível" (DEWEY, 1985b, p. 105). A teoria da educação também deve simplesmente seguir esses dois critérios se não desejar mais ser feudal.

\section{Notas}

1 Tradução de Ana Paula Renesto (doutora em Educação pela Faculdade de Educação da Universidade de São Paulo). Revisão de Claudio A. Dalbosco (professor do Programa de Pós-Graduação em Educação da Universidade de Passo Fundo).

2 Publicado originalmente com o mesmo título em Waks e English (2017).

3 Nota da tradutora: todas as citações ao longo deste texto são traduções livres.

4 Liberty in Education (discurso no Nineteenth Century Club, Nova Iorque, em 1886); Undesirable and Desirable Uniformity in Schools (palestra na National Educational Association, Saratoga, em 12 de julho de 1892); The Function of Education in Democratic Society (discurso no Brooklyn Institute, em 02 de outubro de 1897) (ELIOT, 1909a, p. 123-148; 271-300; 399-418).

5 Artigo "Education", no primeiro volume da enciclopédia de Monroe (DEWEY, 1985a, p. 425-434).

6 Em Atlantic Monthly (fevereiro/março de 1869).

7 Descrito em detalhes em: What is a Liberal Education? (The Century, junho de 1884) (ELIOT, 1909a, p. 87-122).

8 Uma das primeiras traduções que indica a nova abordagem é Herbart (1877).

9 A terminologia empregada por Herbart no original alemão é Geist, que Dewey verte para o inglês como Mind. Para compreender por que se optou pela tradução de Mind como espírito e não simplesmente como mente, ver o ensaio de Claudio A. Dalbosco, neste volume da Espaço Pedagógico (nota do revisor).

\section{Referências}

ANDREWS, C. C. Reflections on the Operations of the Present System of Education. Boston: Crosby, Nichals and Company, 1853.

COMTE RENDU. Comte rendu du Deuxième Congrès International d'Education Morale à La Haye 22-27 Août 1912. Publié par A. G. Dyserinck pour le Comité Exécutif Néerlands. La Haye : Martinus Nijhoff, 1913.

DEWEY, J. How We Think and Selected Essays 1910-1911: The Middle Works 1899-1924, v. 6. Ed. J. A. Boydston, intr. H. S. Thayer e V. T. Thayer. Carbondale/Edwardsville: Southern Illinois University Press, 1985a.

Democracy and Education 1916: The Middle Works 1899-1924, v. 9. Ed. J. A. Boydston, intr. S. Hook. Carbondale/Edwardsville: Southern Illinois University Press, 1985b. 
ELIOT, C. W. Education for Efficiency and The New Definition of the Cultivated Man. Boston; New York; Chicago; Cambridge: Houghton Mifflin Company; The Riverside Press, 1909b. Educational Reform. Essays and Addresses. New York: The Century Co., 1909a. The New Education. Its Organization. Atlantic Monthly, Boston, p. 203-221, 358-367, Feb./Mar. 1869.

GUSKI, A. Metaphern der Pädagogik: Metaphorische Konzepte von Schule, schulischem Lernen in pädagogischen Texten von Comenius bis zur Gegenwart, Bern et al.: Peter Lang Verlag (= Explorationen. Studien zur Erziehungswissenschaft, ed. J. Oelkers, Vol. 53), 2007.

HERBART, J. F. Possibility and Necessity of Applying Mathematics in Psychology. Journal of Speculative Philosophy, Pennsylvania, v. 11, p. 251-264, 1877.

MANSFIELD, E. D. American Education: its principles and elements dedicated to the teachers of the United States. New York: A. S. Barnes \& Co., 1850.

MAYHEW, I. Popular Education. New York: Harper \& Brothers, 1850.

OELKERS, J. Democracy and the two dogmas of Education. In: KOREAN SOCIETY FOR THE STUDY OF EDUCATION (Ed.). The Role of Education in the 21 $1^{\text {st }}$ Century. Seoul: o. J., 2004. p. 27-55.

"Influence" and "Development": two Paradigms of European Educational Theory and the Crisis of the School. In: HELLEMANS, M.; MASSCHELEIN, J.; SMEYERS, P. (Ed.). The school: its crisis. Eduquer après la République. Leuven/Amersfoort: Acco, 1994. p. 95-109.

ROUSSEAU, J.-J. Oeuvres Complètes. T. IV: Emile. Education - Morale - Botanique. Ed. B. Gagnebin e M. Raymond. Paris: Editions Gallimard, 1969.

WAKS, L. J.; ENGLISH, A. John Dewey's Democracy and education: a centennial Handbook. New York: University Press, 2017.

WAYLAND, F. The Education demanded by the people of the U. States. A Discourse Delivered at Union College, Schenectady, July 25, 1854, on the Occasion of the Fiftieth Anniversary of the Presidency of Eliphalet Nott, D.D., L.L.D. Boston: Phillipps, Sampson and Company, 1855. 